\title{
Conteúdos de MATEMÁtica PRESENTES NAS MATRIZES DOS CURSOS DE PEDAgogia Ofertados no Estado do TOCANTINS
}

\author{
CONTENTS OF MATHEMATICS PRESENT IN THE MATRICES OF PEDAGOGY \\ COURSES OFFERED IN THE STATE OF TOCANTINS
}

DOI: http://dx.doi.org/10.23926/RPD.2526-2149.2020.v5.n1.p65-80.id633

\section{Ademir Brandão \\ Costa}

Mestrando em Educação pela

Universidade Federal do

Tocantins (PPPGE/UFT)

ademirbrandao@gmail.com

\section{Ritianne de Fátima \\ Silva de Oliveira}

Mestranda em Educação pela

Universidade Federal do

Tocantins (PPPGE/UFT)

ritianne19@hotmail.com

\section{Maria José de Pinho \\ Doutora em Educação pela \\ Pontifícia Universidade \\ Católica (PUC/SP) \\ Professora na Universidade \\ Federal do Tocantins \\ (PPGE/UFT) \\ mjpgon@mail.uft.edu.br}

\section{Idemar Vizolli}

Doutor em Educação pela

Universidade Federal do

Paraná (UFPR)

Professor na Universidade

Federal do Tocantins

(PPGE/UFT)

idemar@mail.uft.edu.br
Resumo: Reiteradas vezes ouvimos professores que ensinam Matemática nos Anos Inicias do Ensino Fundamental reclamar que em sua formação em nível superior a matemática e seu ensino têm sido relegados ao segundo plano. Isso nos levou a analisar que conteúdos matemáticos se fazem presentes na matriz curricular dos Cursos de Pedagogia ofertados no Estado do Tocantins. Trata-se de um estudo documental, com uma perspectiva metodológica qualitativa, substanciada pela interlocução com a literatura e análise da matriz curricular dos cursos. Os resultados indicam fragilidades no processo de ensino de matemática nos cursos de Pedagogia, em função de que em média $2,56 \%$ a $6,96 \%$ da carga horaria total dos cursos são destinadas ao processo de ensino desta ciência. $\mathrm{O}$ estudo indica que fatores como carga horária reduzida, a falta de conhecimentos matemático dos estudantes, aliados ao viés eminentemente metodológico, a formação desses profissionais fica comprometida e, ao atuarem na docência, sentem-se limitados em sua ação pedagógica.

Palavras-chave: Educação; Ensino de Matemática; Matriz curricular; Curso de Pedagogia.

\begin{abstract}
We have often heard teachers who teach Mathematics in the Early Years of Elementary School complain that, in their higher education, mathematics and its teaching have been relegated to the background. This led us to analyze what mathematical contents are present in the curricular matrix of pedagogy courses offered in the state of Tocantins. This is a documentary study with a qualitative methodological perspective, substantiated by the dialogue with the literature and analysis of the curricular matrix of the courses. The results indicate weaknesses in the process of teaching mathematics in pedagogy courses due to the result that only $2 \%$ to $5.75 \%$ of the total hourly load of the course is destined to the teaching process of this science. The study indicates that factors such as reduced workload, lack of mathematical knowledge of students, combined with eminently methodological bias, the training of these professionals is compromised and, when they act in teaching, they feel limited in their pedagogical action.
\end{abstract}

Keywords: Education; Mathematics Teaching; Curricular matrix; Pedagogy course. 


\section{INTRODUÇÃO}

Há uma grande preocupação em relação aos índices que apuram a qualidade da educação básica em nosso país, sobretudo pelos gestores públicos, gestores educacionais e os próprios professores. Um desses índices observados é a Proficiência que é medida por intermédio do Sistema de Avaliação da Educação Básica (SAEB) ${ }^{1}$.

A proficiência é uma escala de pontuação na qual se considera que o aluno adquiriu ou não o domínio da competência avaliada. Essa pontuação é obtida por meio da Prova Brasil, que faz parte do sistema SAEB e é aplicada de 2 em 2 anos, aos alunos do $5^{\circ}$ e $9^{\circ}$ Anos do Ensino Fundamental. A escala de proficiência é distribuída em 4 níveis, são eles: Insuficiente, Básico, Proficiente e Avançado. A tabela a seguir explana a distribuição dos pontos da escala.

Quadro 1 - Escala de proficiência em matemática

\begin{tabular}{|c|c|c|}
\hline \multicolumn{3}{|c|}{ ESCALA DE PROFICIÊNCIA EM MATEMÁTICA } \\
\hline PROFICIÊNCIA & $\mathbf{5}^{\circ}$ Ano & $\mathbf{9}^{\circ}$ Ano \\
\hline Insuficiente & 0 a 174 pontos & 0 a 224 pontos \\
\hline Básico & 175 a 224 pontos & 225 a 299 pontos \\
\hline Proficiente & 225 a 274 pontos & 300 a 349 pontos \\
\hline Avançado & $\begin{array}{c}\text { Igual ou maior que } \\
\text { 275 pontos }\end{array}$ & $\begin{array}{c}\text { Igual ou maior que } \\
350 \text { pontos }\end{array}$ \\
\hline
\end{tabular}

Fonte: https://www.qedu.org.br

De acordo com o comitê científico do movimento Todos Pela Educação ${ }^{2}$, os estudantes de $5^{\circ}$ Ano têm conseguido desenvolver as habilidades em matemática de forma satisfatória, não que seja o ideal, mas houve evolução. Em 2013, 35\% dos educandos estavam nos níveis Avançado e Proficiente, índices considerados adequados para o ano de estudo. Após a avaliação de 2015 , esse percentual subiu para $39 \%$ e em 2017 , alcançou $44 \%$ de estudantes considerados proficientes no território nacional.

Delimitando-nos aos estudantes do Estado do Tocantins percebemos que os índices não são satisfatórios, tanto que nos anos de 2013 e 2015 somente $28 \%$ dos estudantes alcançou índices de proficiência, ou seja, não houve evolução no período analisado. Somente em 2017 esse índice sofreu uma significativa evolução, onde $37 \%$ dos estudantes foram considerados

\footnotetext{
${ }^{1}$ Criado em 1990 por meio do Plano Decenal de Educação para Todos (1993 - 2003).

${ }^{2}$ É uma organização da sociedade civil, sem fins lucrativos, plural e suprapartidária. https://academia.qedu.org.br
} 
proficientes. Percebe-se que houve um avanço significativo, porém, muito abaixo da média nacional.

Esses índices relacionam-se com as ideias defendidas por Curi $(2004,2005)$, segundo a qual esse quadro pode ser modificado se os cursos que formam os professores que atuam nos anos iniciais derem ênfase ao ensino e aprendizagem da matemática, mesmo porque o futuro professor tem a obrigatoriedade de conhecer profundamente os conceitos matemáticos a serem ensinados às crianças. Ela pondera que há escassez de disciplinas de matemática nos cursos de Pedagogia, seja em relação ao tempo de integralização da disciplina e/ou ausência de um profundo trabalho dos conceitos matemáticos.

\section{Metodologia}

Esse panorama coloca-nos o desafio de analisar as matrizes curriculares dos cursos de Pedagogia ofertados no Estado do Tocantins, a fim de verificar os conteúdos matemáticos presentes, sua carga horária e se eles seguem a tendência nacional. Desse modo, essa pesquisa amparou-se num estudo documental, com uma perspectiva metodológica qualitativa, enquanto o objetivo exploratório e informações colhidas por meio de análises bibliográficas e documentais, substanciada pela interlocução com a literatura e análise da matriz curricular dos cursos.

A investigação teórica apresentada buscou, via Matrizes Curriculares e Projetos Pedagógicos dos Cursos (PPC) de Pedagogia, àqueles em funcionamento até o ano de 2017. Deste modo, revela-se que a análise documental favorece a observação do processo de maturação ou de evolução de indivíduos, grupos, conceitos, conhecimentos, comportamentos, mentalidades, práticas, entre outros (CELLARD, 2008). Bogadane e Biklen (2010, p.49) advogam que a abordagem da investigação qualitativa exige que o mundo seja examinado com a ideia de que nada é trivial, que tudo tem potencial para construir uma pista que nos permita estabelecer uma compreensão mais esclarecedora do nosso objeto de estudo.

Nesse viés, procuramos junto à internet, exclusivamente no site do sistema e-Mec, informações necessárias para buscar responder à questão de pesquisa. Junto aos documentos encontrados identificamos 48 Instituições de Ensino Superior ofertando o curso de Pedagogia no Estado do Tocantins. Dessa forma, localizamos 59 cursos em atividade no território tocantinense, dentre eles, encontramos aqueles que são ofertados em dois, três ou até quatro vezes, em distintas localidades e que, também, são oferecidos em mais de um turno, 
distribuindo-os na modalidade presencial (22\%) e de Educação à Distância (EaD) (78\%). Isso justifica a somatória dos cursos serem superiores à quantidade de Instituições que as ofertam.

Ao consultar as páginas das instituições constatamos que nove instituições não possuíam web site ou não se encontravam disponíveis, adquirimos 39 matrizes curriculares de cursos e somente 7 propostas pedagógicas curriculares (PPC). As tentativas em obtê-las por e-mail resultaram em nenhum retorno. Assim, o universo da pesquisa resultou em 39 matrizes curriculares de cursos de pedagogia oferecidos por instituições públicas e privadas do estado do Tocantins. Dessas, 34 disponibilizaram a relação de disciplinas e as respectivas cargas horárias e cinco disponibilizaram somente a relação das disciplinas. Nesse sentido, optamos por analisar essas matrizes curriculares e continuarmos em busca das ementas para, posteriormente, propor reflexão/discussão/análise minudenciosa.

Segundo informações publicadas no portal e-Mec, metade dessas instituições tem fórum em outros estados da federação, entretanto ofertam os cursos na modalidade $\mathrm{EaD}$, em todas as unidades federativas.

Figura 1 - Organização acadêmica

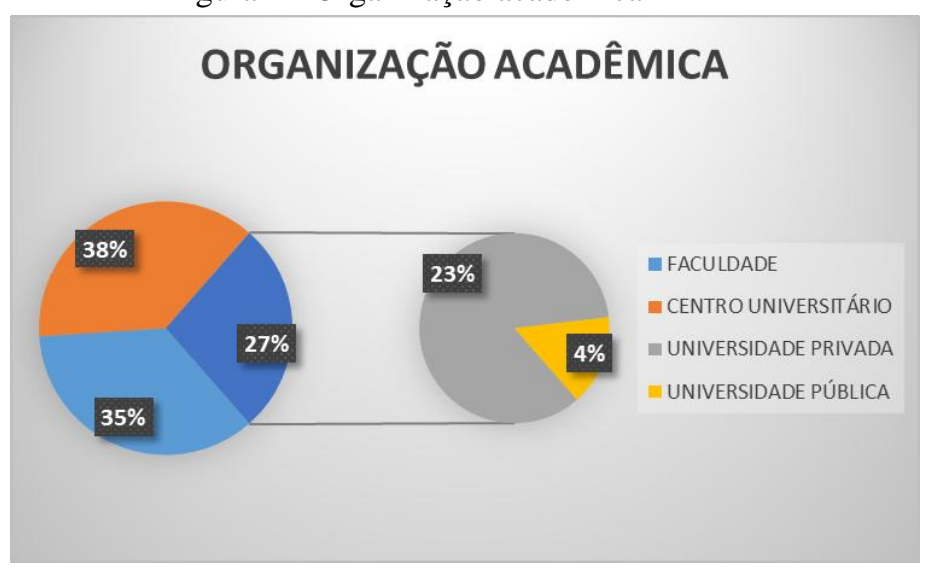

Fonte: Emec/Mec

Das IES pesquisadas 96\% são compostas por Faculdades, Centros Universitários e Universidades privadas e somente 4\% pertencem ao Poder Público. As Faculdades representam 35\% e os Centros Universitários totalizam 38\% (BRASIL, 2019). As Universidades, que juntas somam $27 \%$ das IES, estão em maior número na Rede Privada, representando $23 \%$ do total das Universidades no Estado. Nesse sentido, observa-se que as Instituições Públicas resultam um quantitativo de $4 \%$. Nesse caso, o percentual corresponde à duas instituições, uma Federal e outra Estadual. 
Nesta sequência, traremos informações que nos ajudará a compreender a construção histórica do curso em nosso estado, percebendo as dificuldades e os avanços históricos que o configuraram e que os apresentam, até a data desta pesquisa.

\section{REFERENCIAL TEÓRICO}

A história dos cursos de Pedagogia no Estado do Tocantins possui pouco mais que três décadas, o que significa que o curso foi instalado antes mesmo da criação do Estado. Pinho (2007) relata que o primeiro curso de Pedagogia autorizado foi criado na cidade de Gurupi, em 1987, por meio do "Decreto $n^{\circ}$ 94.787" o qual criava a Faculdade de Filosofia e Ciências Humanas de Gurupi (FAFICH), "mantida pela Fundação Educacional de Gurupi, entidade municipal” (PINHO, 2007, p. 59).

Em 1990, por meio do Decreto ${ }^{\circ}$ 252/90 constitui-se a Fundação Universidade do Tocantins (UNITINS) e com ela a expansão do curso de Pedagogia, passando a ser ofertado em municípios como Arraias, Colinas do Tocantins, Guaraí, Palmas e Tocantinópolis. Em 1999 o campus de Colinas do Tocantins desmembrou-se da UNITINS e passou a se chamar Fundação Municipal de Ensino Superior de Colinas (FIESC), por advento da Lei Municipal nº 705/1999 e pelo Decreto Executivo no 012/1999. No ano 2000, o município de Guaraí assumiu a administração da educação superior e institui uma Fundação Municipal denominada Fundação de Desenvolvimento Educacional de Guaraí, mediante o Parecer nº 5/2000 (PINHO, 2007).

Um novo Estado constituía-se e novas oportunidades surgiam. Nesse interim, IES particulares chegavam ao recém-criado Estado, desse modo, a primeira Instituição privada a oferecer o curso de Pedagogia no Estado foi o Centro Universitário Luterano (ULBRA) instalando-se na capital Palmas, em meados dos anos 1993, logo a diante, chega a Faculdade de Educação, Ciências e Letras de Paraíso (FACIPAR), centralizando-se na cidade de Paraíso do Tocantins durante os anos de 1995. Em Araguaína, no extremo norte tocantinense, outra Instituição se instala e contribui para mudança do cenário da educação superior do Tocantins, ofertando também Licenciatura Plena em Pedagogia, o Instituto Tocantinense Presidente Antônio Carlos (ITPAC), o qual vem investindo na cidade desde o ano de 1998. E no ano de 2002, no município de Porto Nacional se instalou a Faculdade São Marcos (FASAMAR), inaugurando as suas atividades acadêmicas naquela região (PINHO, 2007).

Traina-Chacon e Calderón (2015) afirmam que de 1995 a 2015, o percentual de IES Privadas mais que dobraram; isso se deu por meio da promulgação do Decreto no 2.207/1997, que instituía a distinção institucional no ensino superior. 
Contemplada na Constituição e na LDB, essa diferenciação se concretizou com a criação dos centros universitários, das faculdades integradas, das faculdades e dos institutos superiores ou escolas superiores, cada uma com exigências e atribuições legais claramente definidas. Esse arcabouço legal favoreceu a expansão da educação superior realizada pelo setor privado, além das universidades. (TRAINA-CHACON; CALDERÓN, 2015, p. 86)

Quase no apagar das luzes dos anos 2000 foi criada a Fundação Universidade Federal do Tocantins (UFT), recebendo parte da UNITINS, por intermédio da Lei $\mathrm{n}^{\circ}$ 10.032/2000 e “implantada somente em 2003, quando ocorreu o primeiro concurso público para provimento de vagas de professor assistente e de professor adjunto" (PINHO, 2007, p. 63). E assim, sob a administração da UFT, foram criadas mais turmas de Pedagogia nas cidades de Arraias, Miracema, Palmas e Tocantinópolis.

Pinho (2007) e Rocha (2008) explanam que por um longo período o Estado e os Municípios sofreram com a escassez de professores licenciados para atuar no Ensino Fundamental e Médio, em especial, nos Anos Iniciais do Ensino Fundamental. Relatam também que consórcios, programas e projetos foram implantados na tentativa de amenizar o déficit de profissionais qualificados. "Com índices altos de professores não-habilitados em 1998 tiveram início os primeiros projetos de formação de professores no Estado" (ROCHA, 2008, p. 51), projetos como o Programa de Graduação em Regime Especial, o Programa Especial de Formação Pedagógica para Bacharéis e/ou Tecnólogos e o Projeto Alvorada, foram exemplos de parcerias entre a Secretaria da Educação, Juventude e Esportes do Tocantins (SEDUC/TO) e UNITINS. Entretanto, "no período de 1998 a 2002, o oferecimento de cursos em regime especial tornou-se a opção preferida para agentes educacionais no Estado do Tocantins" (PINHO, 2007, p. 100).

Diante do exposto, percebe-se que a formação inicial em Pedagogia no Território Estadual iniciou-se timidamente, todavia, com a expansão das Instituições de Ensino Superior privadas, muitos municípios foram contemplados com cursos de formação em Pedagogia, tendo em vista que essas instituições conseguiram chegar até as populações que se encontram distante dos grandes centros urbanos, onde se concentra boa parte das IES. O acesso aos cursos nas IES públicas também foram aprimorados, no princípio essa formação era para aqueles que já estavam atuando em sala de aula e não possuíam a formação adequada. Atualmente, as opções de cursar Pedagogia, se espalham pelo Estado, atendendo àqueles que buscam conhecer a educação enquanto ciências e almejam torna-se professor.

O curso de graduação em Licenciatura Plena em Pedagogia regido pelas Diretrizes Curriculares Nacionais, instituído pela Resolução CNE/CP No 1, de 15 de maio de 2006, 
estabelece que tais cursos precisam cumprir uma carga horaria mínima para que possa ser validado. $\mathrm{O}$ Artigo $7^{\circ}$ estabelece assim a distribuição da carga horaria do curso:

O curso de Licenciatura em Pedagogia terá a carga horária mínima de 3.200 horas de efetivo trabalho acadêmico, assim distribuídas:

I - 2.800 horas dedicadas às atividades formativas como assistência a aulas, realização de seminários, participação na realização de pesquisas, consultas a bibliotecas e centros de documentação, visitas a instituições educacionais e culturais, atividades práticas de diferente natureza, participação em grupos cooperativos de estudos;

II - 300 horas dedicadas ao Estágio Supervisionado prioritariamente em Educação Infantil e nos anos iniciais do Ensino Fundamental, contemplando também outras áreas específicas, se for o caso, conforme o projeto pedagógico da instituição;

III - 100 horas de atividades teórico-práticas de aprofundamento em áreas específicas de interesse dos alunos, por meio, da iniciação científica, da extensão e da monitoria. (BRASIL, 2006)

A Diretriz deixa claro que a carga horaria mínima de 2.800 horas é exclusiva às atividades relacionadas às disciplinas que compõem os saberes (Metodologias e Fundamentos), competências e habilidades que serão exigidas dos futuros professores. Já as demais 400 horas, são distribuídas entre estágios supervisionados, com no mínimo de 300 horas e a iniciação científica, extensão e outros com 100 horas (BRASIL, 2006).

O curso de Pedagogia, assim como outras licenciaturas, já foi objeto de pesquisa onde se buscava analisar a qualidade, o tempo de integralização e de dedicação ao estudo das áreas do conhecimento humano. Gatti (2009) organizou uma dessas pesquisas; além da pedagogia, também foram investigadas as licenciaturas em língua portuguesa, matemática e ciências biológicas. Em suas análises e conclusões, especificamente ao curso de Pedagogia, foi constatado que o mesmo apresenta fragilidades em seu currículo e indefinição do que se deve ensinar. Conclui também, que esses fatores podem refletir diretamente na baixa qualidade da educação ofertada aos estudantes dos Anos Iniciais do Ensino Fundamental. Expomos aqui, alguns destaques elaborados a partir do olhar clínico da autora:

- $\quad$ O currículo proposto pelos cursos de formação de professores tem uma característica fragmentária, apresentando um conjunto disciplinar bastante disperso;

- As disciplinas referentes à formação profissional específica apresentam ementas que registram preocupação com as justificativas sobre o por quê ensinar, o que, de certa forma, contribuiria para evitar que essas matérias se transformassem em meros receituários; entretanto, só de forma muito incipiente registram o quê e como ensinar;

- A proporção de horas dedicadas às disciplinas referentes à formação profissional específica é de $30 \%$, ficando $70 \%$ para outro tipo de matérias oferecidas nas instituições formadoras. Cabe a ressalva já feita na análise das ementas segundo a qual, nas disciplinas de formação profissional, predominam os referenciais teóricos, seja de natureza sociológica, psicológica ou outros, com associação em poucos casos às práticas educacionais; 
- Os conteúdos das disciplinas a serem ensinadas na educação básica (Alfabetização, Língua Portuguesa, Matemática, História, Geografia, Ciências, Educação Física) comparecem apenas esporadicamente nos cursos de formação; na grande maioria dos cursos analisados, eles são abordados de forma genérica ou superficial no interior das disciplinas de metodologias e práticas de ensino, sugerindo frágil associação com as práticas docentes (GATTI, 2009, p. 53-54).

Percebe-se na pesquisa de Gatti (2009) que as disciplinas relacionadas aos conteúdos e as metodologias de ensino de matemática estão entre as disciplinas ditas como específicas da profissão. Essas disciplinas são fundamentais para a formação dos professores que ministrarão aulas nos Anos Iniciais do Ensino Fundamental. Pesquisas como a de Fiorentini (2008) nos ajuda a compreender como se encontra o ensino de Matemática nos cursos de Pedagogia.

A reduzida carga didática que os cursos de Pedagogia e Licenciatura para as séries iniciais do Ensino Fundamental têm destinado à formação conceitual e didáticopedagógica da matemática tem sido um problema crônico e que não foi contemplado pelas atuais Diretrizes Curriculares. Além da falta de um domínio conceitual da matemática, os alunos-docentes que ingressam nesses cursos de formação docente trazem crenças e atitudes geralmente negativas e pré-conceituosas em relação à matemática e seu ensino (FIORENTINI, 2008, p. 66-67)

Pesquisadores como Edda Curi, que há muito tempo análise o ensino de matemática por professores polivalentes nos Anos iniciais do Ensino Fundamental, complementa afirmando que essas disciplinas relacionadas à matemática recebem pouco destaque nos cursos de Pedagogia e acrescenta dizendo que:

Considero que os conhecimentos do professor sobre os objetos de ensino devem incluir os conceitos das áreas de ensino definidos para a escolaridade na qual ele irá atuar, mas devem ir além, tanto no que se refere à profundidade desses conceitos como à sua historicidade, sua articulação com outros conhecimentos e o tratamento didático, ampliando assim seu conhecimento da área (CURI, 2005, p. 2).

Lima (2011) reforça que os cursos de pedagogia deveriam possuir em seus currículos,

elementos que permitam construir-se a base de conhecimentos necessários para o professor começar a ensinar Matemática - conhecimento dos conteúdos matemáticos a serem ensinados, seus conceitos fundamentais e a história de tais conceitos; o conhecimento pedagógico geral, que corresponde aos conhecimentos sobre os processos de ensino e aprendizagem de Matemática e aos procedimentos didáticos necessários à transformação do conteúdo a ser ensinado em conteúdo a ser aprendido (LIMA, 2011, p. 191).

Silva e Burak (2017) corroboram com as ideias de Curi e Lima e destacam que "o pedagogo, ao contrário do que muitos acadêmicos mencionam tem o papel de ensinar Matemática para crianças, por isso se faz necessário aprender sobre a área e aprender a ensinar" (SILVA; BURAK, 2017, p. 1.863).

Nesse sentido, percebe-se que o curso de Pedagogia, de forma geral, devido as suas fragilidades, timidamente contribui com o desenvolvimento do saberes necessários ao rol de conhecimento do futuro professor, isso pode acarretar em sucessivas sequências desastrosas de 
professores com formação inadequada e, consequentemente, prejudicar mais ainda os futuros estudantes.

\section{Resultados}

Observamos que $8 \%$ das IES não cumprem às 2.800 horas específicas das áreas de conhecimento humano, metodologias, didáticas, fundamentos, determinado pelas Diretrizes Curriculares Nacionais (BRASIL, 2006). A esse grupo de cursos, apresentam em suas matrizes carga horaria total que variam de 2.900 a 3.100 horas, incluídas ás 400 horas destinadas ao estágio e desenvolvimento de iniciação científica. Por outro lado, em matrizes de $72 \%$ das Instituições pesquisadas, neste contexto, encontramos carga horaria dentre 3.300 a 4.040 . Também há aquelas que seguem as normas, ofertando cursos com carga horaria total mínima de 3.200 horas, esses representam $20 \%$ das IES.

Ao observar a matriz curricular dos cursos de Pedagogia constatamos que a maioria remete aos processos de ensino e aprendizagem de matemática; muitos tratam de conteúdos de estatística e um número significativo versa sobre fundamentos de matemática. Ainda assim, Curi (2005), em investigação que buscou identificar disciplinas da área de matemática presentes nas matrizes dos cursos de Pedagogia, percebeu “(...) pouca presença de conteúdos matemáticos e de suas didáticas nos currículos de cursos de Pedagogia (...)” (2005, p. 8), e há também autores que complementam dizendo que há uma insuficiência de tempo para dedicação ao processo de integralização das disciplinas nas matrizes curriculares. Estudos de Gualberto e Almeida (2009), Souto (2015), Bezerra e Bondezan (2015) e Souza e Borges (2016) indicam que há uma quantidade reduzida de disciplinas de matemática e educação matemática, também há escassez de carga horaria destinada à formação de professores para atuar nos Anos Iniciais do Ensino Fundamental. "É importante que se considere que a frágil formação em matemática interfere diretamente nas relações do estudante com o meio, nas situações cotidianas, bem como para prosseguimento dos estudos" (COSTA; PINHEIRO; COSTA, 2016, p. 520).

Quadro 2 - Carga horária $(\mathrm{Ch})$ dos cursos com uma disciplina relacionada a matemática comparada as Diretrizes Curriculares Nacionais do Curso de Pedagogia (DCNCP)

\begin{tabular}{|c|c|c|c|c|c|}
\hline $\mathbf{C h}_{\mathbf{1}}$ & $\mathbf{C h}_{\mathbf{2}}$ & $\mathbf{C h}_{\mathbf{3}}$ & $\mathbf{C h}_{\mathbf{4}}$ & $\mathbf{C h}_{\mathbf{5}}$ & $\begin{array}{c}\mathbf{C h} \\
\text { DCNCP }\end{array}$ \\
\hline 56 & 60 & 72 & 80 & 100 & 2.800 \\
\hline $2 \%$ & $2,14 \%$ & $2,57 \%$ & $2,86 \%$ & $3,57 \%$ & $100 \%$ \\
\hline
\end{tabular}

Fonte: Elaborado pelos autores 
A relação de disciplinas presentes em cursos que oferecem uma única disciplina representa $44 \%$ dos cursos pesquisados. Dentre as 39 matrizes curriculares adquiridas junto às páginas virtuais das IES observou-se que as disciplinas que estão diretamente relacionadas à educação matemática e a própria matemática sejam nos seus fundamentos teóricos ou as suas metodologias de ensino ou disciplinas que apresentam o conjunto teoria e prática. As disciplinas encontradas nesses cursos dão ênfase aos fundamentos ou as metodologias de ensino de tal disciplina, há casos em que a mesma disciplina oferta tanto os fundamentos, quanto as metodologias de ensino, sendo que a carga horaria dispendida a tais disciplinas variam de 56 a 100 horas de atividades teóricas e práticas. Tomando como parâmetro o mínimo de 2.800 horas que o curso deve oferecer em todo o currículo aos estudantes percebemos que o percentual da carga horaria destinada a tais disciplinas variam de $2 \%$ a $3,57 \%$ do quantitativo mínimo estabelecido nas Diretrizes Curriculares Nacionais do Curso de Pedagogia.

Quadro 3 - Carga horária $(\mathrm{Ch})$ dos cursos com duas disciplinas relacionadas à matemática comparadas as Diretrizes Curriculares Nacionais do Curso de Pedagogia (DCNCP)

\begin{tabular}{|c|c|c|c|c|c|c|c|c|c|c|}
\hline $\mathbf{C h}_{\mathbf{6}}$ & $\mathbf{C h}_{\mathbf{7}}$ & $\mathbf{C h} \mathbf{8}$ & $\mathbf{C h} \mathbf{9}$ & $\mathbf{C h}_{\mathbf{1 0}}$ & $\mathbf{C h}_{\mathbf{1 1}}$ & $\mathbf{C h}_{\mathbf{1 2}}$ & $\mathbf{C h}_{\mathbf{1 3}}$ & $\mathbf{C h}_{\mathbf{1 4}}$ & $\mathbf{C h}_{\mathbf{1 5}}$ & $\mathbf{C h} \mathbf{D C N C P}$ \\
\hline 70 & 90 & 100 & 108 & 110 & 120 & 135 & 136 & 144 & 160 & 2.800 \\
\hline $2,50 \%$ & $3,21 \%$ & $3,57 \%$ & $3,86 \%$ & $3,93 \%$ & $4,28 \%$ & $4,82 \%$ & $4,86 \%$ & $5,14 \%$ & $5,71 \%$ & $100 \%$ \\
\hline
\end{tabular}

Fonte: Elaborado pelos autores

Identificamos que em $47 \%$ das matrizes investigadas há oferta de duas disciplinas; as de fundamentos da matemática e as metodologias de ensino. Com essa ampliação do número de disciplinas normalmente reconhecemos um ganho em carga horária nas disciplinas dos cursos pesquisados. Isso preconiza a ideia de maior dedicação aos estudos dos assuntos e conteúdos relacionados à matemática e a educação matemática. Essas disciplinas disponibilizam carga horaria que variam de 70 a 160 horas em seu somatório. Comparando com a carga horaria total dos cursos estabelecida pelas DCNCP, esses apresentam percentuais de representatividade de disciplinas de matemática e educação matemática no intervalo entre $2,50 \%$ e $5,71 \%$.

Nota-se também, que o enfoque das disciplinas de menor carga horaria é destinado à questão do saber matemático do professor que lecionará nos Anos Iniciais do Ensino Fundamental. Disciplinas como: Matemática, Matemática e Estatística, Estatística aplicada a Educação e Lógica Matemática, ressaltam a importância em dominar o saber matemático por meio da sistematização dos conteúdos. Do outro lado, disciplinas como: Metodologia e Prática 
da Matemática, Educação Matemática e Metodologia do Ensino da Matemática, dedicam-se ao saber didático-metodológico do ensino e aprendizagem da matemática Curi (2004).

Quadro 4 - Carga horária (Ch) dos cursos com três disciplinas relacionadas a matemática comparadas as Diretrizes Curriculares Nacionais do Curso de Pedagogia (DCNCP)

\begin{tabular}{|c|c|c|c|c|}
\hline $\mathbf{C h}_{16}$ & $\mathbf{C h}_{17}$ & $\mathbf{C h}_{18}$ & $\mathbf{C h}_{19}$ & $\begin{array}{c}\text { Ch } \\
\text { DCNCP }\end{array}$ \\
\hline 160 & 180 & 200 & 240 & 2.800 \\
\hline $5,71 \%$ & $6,43 \%$ & $7,14 \%$ & $8,57 \%$ & $100 \%$ \\
\hline
\end{tabular}

Fonte: Elaborado pelos autores

De todo o conjunto de matrizes pesquisadas apenas $9 \%$ dos cursos oferece um maior rol de conhecimento relacionado à matemática e à educação matemática aos futuros professores dos Anos Iniciais do Ensino Fundamental. Esses cursos ofertam em suas matrizes três disciplinas e as dissociam completamente, ofertando de 160 a 240 horas de atividades dedicadas às teorias e as práticas, seja na aquisição dos saberes matemáticos, ou pela obtenção de técnicas e metodologias de ensino pelos professores. Para esses cursos o percentual da carga horaria dessas disciplinas variam de $5,71 \%$ a $8,57 \%$.

Quadro 5 - Grupos de disciplinas, somatório de carga horaria, média aritmética da carga horaria e percentual da média aritmética da carga horaria comparada as Diretrizes Curriculares Nacionais do Curso de Pedagogia (DCNCP)

\begin{tabular}{|c|c|c|c|}
\hline Grupo & $\sum \mathbf{C h}$ & $\boldsymbol{X}_{\mathbf{C h}}$ & \% $\boldsymbol{X}_{\mathbf{C h}}$ \\
\hline 1D & 860 & 71,67 & 2,56 \\
\hline 2D & 3.566 & 118,87 & 4,24 \\
\hline 3D & 2.340 & 195 & 6,96 \\
\hline
\end{tabular}

Fonte: Elaborado pelos autores

Ao observamos a carga horaria total dos cursos que oferecem somente uma disciplina verificamos que o somatório da carga horaria dessa única disciplina representa, em média, 2,56\% do mínimo estabelecido em lei, já naqueles cursos que oferecem duas disciplinas, computamos um percentual médio de $4,24 \%$, isso representa dois quintos a mais em relação àqueles cursos que ofertam apenas uma disciplina. Por fim, os cursos de Pedagogia que ofertam três disciplinas, representam uma média de 6,96\% da carga horaria pré-estabelecida em lei, mais que o somatório dos percentuais daqueles cursos que ofertam uma ou duas disciplinas. Sendo que, para os cursos que oferecem três disciplinas, isso representa aproximadamente dois terços a mais em relação aos cursos com uma única disciplina e dois quintos a mais comparada ao percentual dos cursos com duas disciplinas. Isso nos dá uma ideia quantitativa da presença dessas disciplinas nos cursos pesquisados. 
Verificou-se que em 53\% das matrizes curriculares dos cursos de Pedagogia estão presentes disciplinas cuja preocupação está com a didática e a metodologia do ensino da Matemática.

Fundamentos e Metodologias do Ensino da Matemática com 29\%, Conteúdos, Metodologia e Prática do Ensino de Matemática 7\%, Matemática e Suas Metodologias de Ensino 6\%, Metodologia e Prática do Ensino da Matemática e Ciências 5\%, Fundamentos e Didática da Matemática 3\% e Fundamentos e Prática do Ensino da Matemática 3\%, compõem o quadro de disciplinas que fornecerá "elementos teórico-metodológicos para o ensino da Matemática ao professor que atuará nos anos iniciais da educação básica" (FERREIRA e PASSOS, 2013, p. 31.139).

Os componentes curriculares citados anteriormente são importantes para o desenvolvimento do ensino-aprendizagem e para a construção de um arcabouço metodológico no estudante de pedagogia para que possa suprir os futuros questionamentos de seus alunos nos anos iniciais do Ensino fundamental.

Porém,

é possível considerar que os futuros professores concluem cursos de formação sem conhecimentos de conteúdos matemáticos com os quais irão trabalhar, tanto no que concerne a conceitos quanto a procedimentos, como também da própria linguagem matemática que utilizarão em sua prática docente. (CURI, 2004, p. 76-77)

Em sua pesquisa, ao analisar as matrizes curriculares de 36 cursos de Pedagogia, foi evidenciado que a carga horaria destinada à formação do professor, no tocante a disciplina Matemática, é insuficiente para uma formação consistente; também destacou a necessidade de expandir a carga horaria para a formação matemática nesses cursos e que essa carência possivelmente seria corrigida por meio de uma formação continuada focada na correção dessa lacuna deixada pela formação inicial (CURI, 2004).

Em pesquisa realizada com alunos do curso de pedagogia da Universidade Federal da Paraíba, na qual Alves e Cavalcante (2018) investigaram as concepções dos estudantes antes e depois da apresentação do componente curricular Ensino de Matemática, apurou-se que tais estudantes tinham certa resistência e temor em relação à disciplina e ensiná-la não seria uma missão prazerosa.

As pesquisadoras destacam que foi possível gerar novas aprendizagens e amenizar o medo de aprender e de ensinar Matemática. Os estudantes de pedagogia perceberam que a forma como se ensina influencia bastante no aprendizado, contudo, frisam ainda que "o contato com os conhecimentos da Matemática vem sendo considerado insuficiente e isso ocorre desde 
os cursos de formação de professores das Escolas Normais até nos cursos dos dias atuais" (ALVES e CAVALCANTE, 2018, p. 82).

A convergência nos estudos de Curi (2004) e de Alves e Cavalcante (2018) detectaram a escassez de tempo na formação do pedagogo para lecionar matemática nos Anos Iniciais do Ensino Fundamental. Nas pesquisas de Lima (2011), na qual foram analisadas 71 matrizes curriculares de cursos de Pedagogia espalhados pelo país foi diagnosticado que $40 \%$ das cargas horarias dos cursos são destinadas as disciplinas de Filosofia, Sociologia, Psicologia, ou seja, os cursos "restringem-se a preparar teoricamente o acadêmico" deixando "pouco espaço para os conteúdos específicos das disciplinas e para os aspectos didáticos do trabalho docente".

O problema é que o curso não consegue articular teoria e prática, pois, no momento de dar ao aluno uma visão prática do que é ensinar, utilizando as outras disciplinas que são para este fim, não se mostra capaz de aproximar os futuros professores da realidade do ensino na sala de aula. (LIMA, 2011, p. 49)

Nossos estudos também identificaram essa baixíssima carga horaria destinadas ao ensino da Matemática nos cursos de Pedagogia ofertados no Estado do Tocantins. Há uma variação média na carga horaria destinada a essas disciplinas entre 2\% a 8,57\% (Vide Quadro 2; Quadro 3 e Quadro 4). Esses dados assemelham-se com a média nacional, relatado na pesquisa de Fiorentini (2008), onde encontrou percentuais na casa dos $4 \%$. Isso nos indica que é uma situação comum em todo país e, tomando como base a literatura disponível, podemos afirmar que o ensino das demais disciplinas: Português, História, Geografia, Ciências, Educação Física e Alfabetização, também são prejudicados pela insuficiência de tempo.

\section{CONSIDERAÇÕES FINAIS}

Esse trabalho analisou matrizes curriculares dos cursos de Pedagogia ofertados no Estado do Tocantins. Detectamos nessas matrizes que $8 \%$ dos cursos possuem carga horaria inferior à estabelecida pela Resolução $\mathrm{CNE} / \mathrm{CP}^{\circ} \mathrm{N}^{\mathrm{o}} 1 / 2006$, não cumprindo com a carga horaria mínima exigida para o curso, que é de 2800 horas destinadas às disciplinas, fragilizando mais ainda a formação dos professores. Enquanto $20 \%$ dos cursos cumprem a norma, aplicando exatamente a carga horaria destinada ao curso, outros $72 \%$ ofertam mais do que o estabelecido em lei, chegando exceder 4.000 horas. Isso não significa que haverá aprendizado satisfatório, mas oportuniza mais tempo de dedicação às disciplinas mais complexas, como é o caso da matemática.

Em relação às disciplinas relacionadas à matemática, a carga horaria apresentada nas matrizes é considerada modesta. Isso, considerando as ideias anteriormente defendidas nesta 
pesquisa. Nesse sentido, observamos que $44 \%$ das matrizes que ofertam apenas uma disciplina relacionada à matemática, possui carga horaria média de $2,56 \%$ em ralação ao estipulado na Resolução supracitada que é de 2.800 horas, destinados às disciplinas nos cursos de Pedagogia. Já àquelas com duas disciplinas voltadas a assuntos relativos à matemática, representam $47 \%$ dos cursos e constam com média de 4,24\%. Seguindo esse raciocínio, encontramos cursos ofertando três disciplinas, que relativamente representam média de $6,96 \%$ da carga horaria total do curso, esse quantitativo de carga horaria consta em $9 \%$ dos cursos pesquisados.

Observamos também que as disciplinas voltadas à Didática e a Metodologia do Ensino de Matemática estão presentes em 53\% dos cursos; isso reforça a ideia de que os cursos pouco se dedicam aos conceitos e fundamentos da matemática para o ensino.

Por fim, ficou evidente que os cursos seguem um viés mais teórico metódico. Teórico no que tange aos conceitos da formação pedagógica e filosófica. Metódico na dedicação aos métodos e técnicas de ensinar, sendo que a parte conceitual deixa a desejar. Deste modo, pretendemos com este trabalho, ampliar o debate a respeito da importância das disciplinas de matemática voltadas tanto aos fundamentos, quanto as metodologias, apresentadas nos cursos de Pedagogia. De todo modo, este trabalho está em fase de construção e como dito anteriormente, faz parte de uma pesquisa maior.

\section{REFERÊNCIAS}

ALVES, Francisca Terezinha Oliveira; CAVALCANTE, Rosicláudia Bezerra. Ensino de Matemática no curso de Pedagogia: Concepções dos graduandos sobre suas aprendizagens. Revista Educação Matemática Em Foco, v. 6, n. 2, p. 78-101, 2018.

BEZERRA, Renata Camacho; BONDEZAN, Andreia Nakamura. O ensino da Matemática no curso de Pedagogia/PARFOR: Refletindo a formação de professores. Trilhas Pedagógicas, Pirassununga - SP, 5, n. 5, 2015. 122-133. Disponivel em: http://www.fatece.edu.br/arquivos/arquivos\%20revistas/trilhas/volume5/8.pdf. Acesso em: 01 Mar 2019.

BODGAN, Robert; BIKLEN, Sari Knopp. A investigação qualitativa em educação. Porto/Portugal: Porto editora, 2010.

BRASIL. e-MEC. emec.mec.gov.br, 2019. Disponível em: http://emec.mec.gov.br. Acesso em: 28 Jan 2019.

BRASIL, Conselho Nacional de Educação, Conselho Pleno. Resolução CNE/ CP n ${ }^{\circ}$ 01, de 15 de maio de 2006, Brasília, 2006.

CELLARD, André. A análise documental. In: POUPART, Jean. et al. A pesquisa qualitativa: enfoques epistemológicos e metodológicos. Petrópolis, Vozes, 2008. 
COSTA, Jaqueline de Morais; PINHEIRO, Nilcéia Aparecida Maciel; COSTA, Ercules. A formação para matemática do professor de anos iniciais. Ciência \& Educação, Bauru - SP, 22, n. 2, 2016. 505-522. Disponível em:

https://dialnet.unirioja.es/servlet/articulo?codigo=5562741. Acesso em: 21 Jan 2019.

CURI, Edda. Formação de professores polivalentes: uma análise dos conhecimentos para ensinar matemática e das crenças e atitudes que interferem na constituição desses conhecimentos. Tese de Doutorado (Educação Matemática), Pontifícia Universidade Católica PUC - SP, São Paulo, 2004.

CURI, Edda. A formação matemática de professores dos anos iniciais do ensino fundamental face às novas demandas brasileiras. Revista Iberoamericana de Educación, v. 37, n. 5, p. 1$10,2005$.

FERREIRA, Viviane Lovatti; PASSOS, Laurizete Ferragut. Metodologia do Ensino de Matemática: Uma análise de programas de ensino dos cursos Pedagogia. Anais do XI Congresso Nacional de Educação - EDUCERE 2013, Curitiba - PR, set., p. 31139-31155, 2013. Disponível em: http://educere.bruc.com.br/CD2013/pdf/7174_5209.pdf. Acesso em: 15 jan. 2019.

FIORENTINI, Dario. A pesquisa e as práticas de formação de professores de Matemática em face das políticas públicas no Brasil. Bolema-Boletim de Educação Matemática, Rio Claro SP, v. 29, p. 43-70, 2008.

SILVA FILHO, Aloisio Machado. A importância da estatística na formação do profissional pedagogo. Cairu em Revista: Sociedade, Educação, Gestão e Sustentabilidade, Salvador - BA, v. 3, n. 3, 2014. Disponível em:

https://www.cairu.br/revista/arquivos/artigos/2014/Artigo_IMPORTANCIA_ESTATISTICA. pdf. Acesso em: 21 Jan 2019.

GATTI, Bernardete Angelina. Análise dos cursos presenciais de licenciatura em Pedagogia. In: GATTI, Bernardete Angelina; NUNES, Marina Nuniz Rosa. Formação de professores para o ensino fundamental: estudo de currículos das licenciaturas em pedagogia, língua portuguesa, matemática e ciências biológicas. Textos FCC. São Paulo - SP: FCC/DPE, 2009. p. 11-56.

GUALBERTO, Priscila Mara de Araújo; ALMEIDA, Rafael. Formação de professores das séries iniciais, algumas considerações sobre a formação matemática e a formação dos professores das licenciaturas em pedagogia. Olhar de Professor, Ponta Grossa - PR, 12, n. 2, 2009. 287-308. Disponivel em: https://www.redalyc.org/pdf/684/68419274004.pdf. Acesso em: 09 Jan 2019.

LIMA, Simone Marques. A formação do pedagogo e o ensino da matemática nos anos iniciais do ensino fundamental. Dissertação (mestrado) - Universidade Federal de Mato Grosso, Instituto de Educação, Programa de Pós-Graduação em Educação, Cuiabá - MT, 2011.

PINHO, Maria José de. Políticas de formação de professores: intenção e realidade. Cânone Editorial, Goiânia, 2007. 
ROCHA, José Damião Trindade. Sentidos, concepções e discursos da formação de professores no Brasil no final do século XX: respingos e estilhaços na educação do Tocantins. In: DOURADO, Luiz Fernandes, OLIVEIRA, João Ferreira. (Org.). Políticas e Gestão da Educação no Tocantins: múltiplos olhares. 1ed.São Paulo: Xamã Editora, 2008, v. P769, p. $37-56$

SILVA, Vantielen da Silva.; BURAK, Dionísio. A formação de pedagogos para o ensino de matemática nas Universidades Estaduais do Paraná: Reflexões iniciais. EDUCERE: XII Congresso Nacional de Educação, Curitiba - PR, p. 1859-1872, 2017. Disponível em: http://educere.bruc.com.br/arquivo/pdf2017/24988_12197.pdf. Acesso em: 29 Jan 2019.

SOUTO, Nayara Mariano. Percepções de estudantes de Pedagogia em relação à própria formação matemática: um estudo com duas instituições mineiras. XIX EBRAPEM Encontro Brasileiro de Estudantes de Pós-Graduação em Educação Matemática, Juiz de Fora - MG, 2015. Disponivel em: http://www.ufjf.br/ebrapem2015/files/2015/10/gd7_Nayara_Souto.pdf. Acesso em: 14 Jan 2019.

SOUZA, Kelly Cristine Silva; BORGES, Marcos Francisco. A formação matemática dos professores dos Anos Iniciais do Ensino Fundamental para a docência. XII Encontro Nacional de Educação Matemática - ENEM, São Paulo - SP, 2016. Disponivel em: http://www.sbembrasil.org.br/enem2016/anais/pdf/5627_2384_ID.pdf. Acesso em: 15 Mar 2019.

TRAINA-CHACON, José-Marcelo; CALDERÓN, Adolfo-Ignacio. A expansão da educação superior privada no Brasil: do governo de FHC ao governo de Lula. Revista Iberoamericana de Educación Superior, v. 6, n. 17, p. 78-100, 2015. Disponível em: https://www.sciencedirect.com/science/article/pii/S2007287215000372. Acesso em: 18 jan 2018.

Recebido em: 27 de fevereiro de 2020.

Aprovado em: 30 de março de 2020. 